\title{
Peak Electricity Demand Prediction Model for Sri Lanka Power System
}

\author{
G.V.Buddhika De Silva and Lalith A. Samaliarachchi
}

\begin{abstract}
Accurate prediction of daily peak electricity demand is a requirement for service reliability, system stability and operating performance of a power system in the field of electrical engineering. This has now become a very important factor for Sri Lanka power system, since the available power plants are to be dispatched in an economical and reliable manner especially during the peak demand period of the chronological load profile. Therefore the prediction of next day peak electricity demand to an acceptable accuracy is useful for the system control centre (SCC) of the Ceylon Electricity Board (CEB). However, presently the unit commitment to meet the next day peak electricity demand is being mostly done by the system control engineers based on their past experience in the field of operation with respect to the day, period and other factors. This research paper carefully identifies sensitive elements which affect the daily peak demand of Sri Lanka power system and develop two forecasting models, namely linear statistical "Multiple Regression" and feed forward "Artificial Neural Network". Both models were developed and fine-tuned using recorded peak demands of Sri Lanka power system from year 2008 to 2011 taken from the SCC of CEB and tested for the calendar year 2012 and also for the first few months of 2013. Artificial Neural Network model was found to be the best fit model for the prediction of daily peak demand of Sri Lanka power system with the lowest Mean Absolute Percentage Error (MAPE).
\end{abstract}

Keywords: Artificial Neural Networks, Multiple Regression Analysis, peak demand

\section{Introduction}

\subsection{Objective}

This paper discusses step by step development of a best fit forecasting model for the prediction of next day peak electricity demand of Sri Lanka power system. Such a prediction model will not only help the System Control Engineers to prepare optimum allocation of generation, unit commitment and hydro/thermal coordination but also for the preparation of short term planned outages for scheduled maintenance of power plants eventually contributing to the system to maintain its stability and reliability.

\section{$1.2 \quad$ Background}

One of the major and also a difficult task of a system control engineer is to prepare a plan showing the next day's expected peak electricity demand and its associated optimum generation dispatch. Presently, this is being done based on past experience with respect to various factors by system control engineers and it involves lots of risks. Therefore the prediction of next day peak electricity demand to certain accuracy would help the system control centre to ride through the critical period without facing many difficulties.

\section{$1.3 \quad$ Features}

It has been noticed that the demand for electricity in Sri Lanka grows steadily and continuously specially after the 30 year long civil war. Social life patterns and day to day activities of Sri Lanka exhibit two peak demand periods in chronological daily load profile [6] as shown in figure 1 . One is in the day time and the other during night time. Night peak demand is the highest and control engineers are very much concerned about.

Being a diverse country, home to many religions and ethnicities, peak electricity demand in Sri Lanka is mostly affected by official/non official holidays and also by religious and cultural events. Sri Lankan government offers 25 formal annual holidays and could be divided into two main groups such as P.B.M [Public, Bank and Mercantile] and PB [Public and Bank]. Peak electricity demand is observed to be different on a monthly Buddhist holiday called "Poya day". Sinhalese and Tamil Cultural/Festival seasons,

Eng. G.V.Buddhika De Silva, B. Tech. Eng. (Hons), Open University of Sri Lanka (OUSL), AMIE (Sri Lanka) Eng. Lalith A. Samaliarachchi, B. Sc. Eng. (Hons) (Moratuwa), M. Eng.(AIT), MIET(UK), MIE(Sri Lanka), C.Eng Senior Lecturer, Department of Electrical $\mathcal{E}$ Computer Engineering, OUSL. 


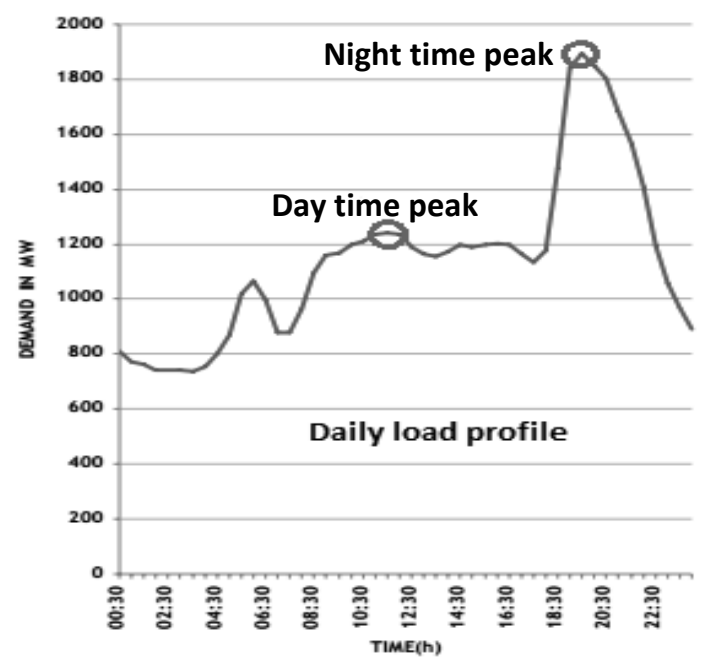

Figure 1 - Chronological Daily Load Profile

identified as "New Year Season" during April and Buddhist religious activities during "Wesak" week in May show a unique but unsteady peak demand pattern and needed to be treated separately from the regular days. Peak demand value variation owing to the temperature and humidity changes and the impact owing to night time cricket matches such as ODIs \& T20s during peak demand hours are noted and also needed to be considered.

\section{$1.4 \quad$ Forecasting}

Two mathematical forecasting techniques are considered in this study and they are:

- Multiple Regression analysis (MRA)

- Artificial Neural Networks (ANN)

Basically MRA is a linear statistical model traditionally used for forecasting and in here it is used to identify the relationships between the peak demand and its dependent variables. Statistical significance of each dependent variable has to be considered here.

The aim of using ANN is to model any non linear complex relationships, if exists, between the variables that cannot be identified with traditional linear models. ANN has to be trained first and checked its ability for generalization [lowest output errors for the inputs which have not seen before].

Since most of the forecasting techniques are lagged behind their theoretical formulation and verification in the field of operation, study compares and identifies the best fit model for the prediction of peak electricity demand.

\section{Literature Survey}

It has been observed that the wide variety of forecasting techniques are being used for the prediction of short term electricity demand, such as Similar Day approach, Time series methods (Autoregressive Moving Average ARMA), Autoregressive Integrated Moving Average (ARIMA), autoregressive integrated moving average with exogenous variables (ARIMAX), Multiple Regression Analysis, Artificial Neural Networks, Expert Systems, Fuzzy logic, Support vector machines [4] and Exponential smoothing methods [9].

ANN has been used and tested for the hourly demand prediction model developed for the Western part of Saudi Arabia [7]. Nigerian Electrical Power System [8] and South Sulewesi's (Sulewesi Island-Indonesia) Power System have used multiple regression analysis [5] for the development of a demand prediction model. However, it was noted that very few publications have apparently verified the goodness of fitness of the developed models against actual values.

\section{Methodology}

\subsection{Multiple Regression Analysis}

In here, the dependent variable peak demand $(\mathrm{P})$ can be expressed as a function of many independent variables

$$
\begin{gathered}
\mathrm{P}=\mathrm{a}_{1}+\mathrm{a}_{2} \times \mathrm{X}_{\mathrm{a}}+\mathrm{a}_{3} \times \mathrm{X}_{\mathrm{b}}+\mathrm{a}_{4} \times \mathrm{X}_{\mathrm{c}}+\mathrm{a}_{5} \times \mathrm{X}_{\mathrm{d}}+ \\
\mathrm{a}_{6} \times \mathrm{X}_{\mathrm{e}}+\text { Error }
\end{gathered}
$$

SPSS 16.0 (Statistical Package for the Social Sciences) software package is used to do MRA throughout the study. Embedded F \& T tests in SPSS compares the sample data with the main distribution by making hypothesis and explore whether the regression results are owing to the random effect. The four basic assumptions to be fulfilled before the correctness of the results of MRA is verified are Linearity, Independence of residuals, Normality of residuals and Homoscedasticity [1] \& [12].

An observation that is numerically distant from the rest of the data called "outlier" can lead regression estimates to be inaccurate and limit the ability to understand data. In this study outliers were identified by the scatter plot between residuals Vs predicted values. Common thresholds are $|2.0|$ or $|3.0|$ times the standard deviations [11] from error mean. 
To have an efficient regression results, those outliers have to be removed from the data and analysis should be redone until all the standardized residuals are within the acceptable limits.

The block diagram for the algorithm showing how the MRA model is developed and finetuned is given in Appendix A1, figure A1.

\subsection{Artificial Neural Network}

Neural networks are adaptive statistical models based on an analogy of the structure of human brain. It can be fine-tuned to estimate the parameters of the population utilizing limited number of exemplars (one or few) at a time. ANN maps an input space in to the desired output space by adjusting the connecting weights and biases (called learning). There are two methods of learning; "Supervised learning and unsupervised learning". Supervised learning method is used in this paper analogue to the student guided by the teacher as shown in figure 2.

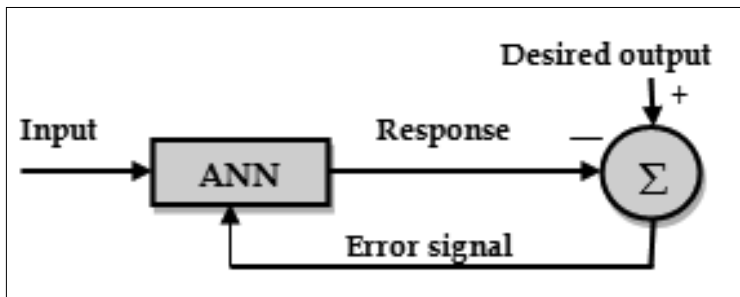

Figure 2- Supervised Learning Method

A single neuron model shown in figure 3 has multiple inputs $(X)$ and a single output $(Y)$. Each input is modified and multiplied by a weight $(W)$. Weighted inputs are combined at a Summing point. Output will be determined with reference to the activation function (f) and threshold value $(\theta)$.

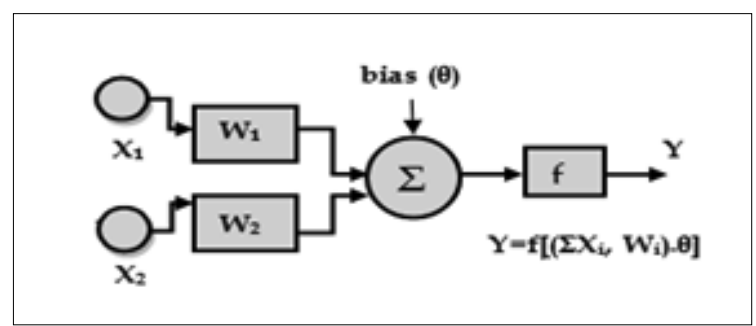

Figure 3 - Single Neuron Model

Neurons are organized to make up the neural network structures and the most concerned structure is the multilayer network. When the network is a feed forward ANN, signals travel only in one direction. Output of one layer will be the input for the following layer.

In this paper, two layer ANN architecture i.e. with one hidden layer and one out put layer were used. Figure 4 exhibits a two layer feed forward ANN structure.

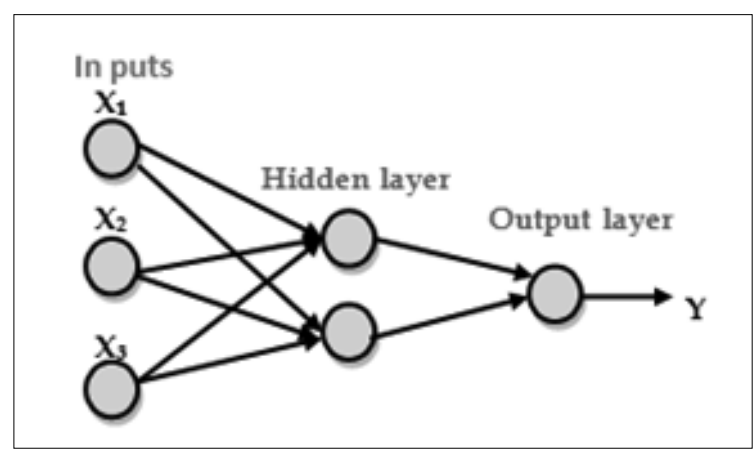

Figure 4 - Two Layer Feed Forward ANN

For the preparation ANN model, two ANN architectures were treated and developed using three activation functions "Tan-sigmoid", "logsigmoid" and "pure linear" [2, 3 \&10]. Deciding the number of hidden neurons in layers is an important part while developing the overall ANN architecture. Two traditional approaches were used in this study to find out the number of neurons in hidden layers and they are:

- Try different configurations, see what works best

- Rule of thumb methods.

Latter provides a starting point to consider.

\subsection{Data Pre-Processing}

While "Statistical or Z- Score Normalization" technique is used to normalize the inputs and targets to improve the training process, principal component analysis is used to reduce the dimensions of the inputs which have high correlations between their components[3 \&10].

\subsection{Training of Artificial Neural Network} Training of the ANN architecture needs to be done by using four different training methods [10] and could be stated as:

- trainbr - Automated Regularization

- trainlm- Reduced Memory Levenberg- Marquardt

- traingdx-Variable Learning Rate Back propagation

- trainrp - Resilient Back propagation 
The block diagram for the algorithm showing how the ANN model is prepared and fine-tuned is given in Appendix A2, figure A1

\section{Data Input}

Observed peak demand data and its associated variables identified in 1.3 from calendar year 2008 to 2011 are carefully sorted out, treated and analysed for both forecasting models.

Table 1 - Input variables

\begin{tabular}{|c|l|}
\hline $\begin{array}{c}\text { Independent } \\
\text { Variables }\end{array}$ & \multicolumn{1}{|c|}{ Data Input } \\
\hline Year & $2000-0 . \ldots, 2012-12$ \\
\hline Week & $1-52$ \\
\hline Day & Mon.=1...Sun. $=7$ \\
\hline Temperature & Forecast temp. \\
\hline Relative Humidity & Forecast RH \\
\hline P.B. holiday & $0 . .1 .$. \\
\hline P.B.M holiday & $0 \ldots 1 .$. \\
\hline Poya day & $0 \ldots . .$. \\
\hline New year week & $0 \ldots . .$. \\
\hline Wesak Week & $0 \ldots . .1$. \\
\hline ODI or T20 & $0 \ldots 1 .$. \\
\hline
\end{tabular}

Numerical indexes are given to represent the data input vector as depicted in table 1 to get the output for forecasted day peak. Daily Temperature and Relative humidity values were taken as the mean hourly values recorded between 4.40 p.m to 8.40 p.m at Katunayaka [13].

\section{Results}

\subsection{Results of MRA}

Multiple regression Analysis is carried out for both linear and exponential models. Exponential model of MRA is shown to be the best fit and seven equations were totally derived to represent the final forecast, one per each day. The Results of MRA model applied to the calendar year 2012 is shown in Appendix A1, figure A2. A significant deviation between the actual [14] and the forecast peak value has been observed for 64 out of 365 days owing to the unprecedented power cuts and other inherent features such as peak power saving strategies imposed by CEB from time to time. However, results of MRA revealed a Mean Absolute Percentage Error (MAPE) of $4.72 \%$ for 301 out of 365 consistent data.

\subsection{Results of ANN}

The best ANN architecture model giving lowest MAPE for the daily peak demand prediction of year 2012 is given in table 2 .

Table2-The Best Neural Network Architecture

\begin{tabular}{|c|c|}
\hline Description & ANN structure \\
\hline No of hidden layers & 1 \\
\hline No of Hidden neurons & 17 \\
\hline $\begin{array}{c}\text { Activation function of } \\
\text { hidden layer }\end{array}$ & Tan- Sigmoid \\
\hline $\begin{array}{c}\text { Activation function of } \\
\text { out put layer }\end{array}$ & Pure linear \\
\hline $\begin{array}{c}\text { No of neurons in the } \\
\text { output layer }\end{array}$ & traingdx \\
\hline Training function \\
\hline
\end{tabular}

The results of ANN model is shown in Appendix A2, figure A2. The deviation between the actual and the forecasted peak cannot be overemphasized here again owing to the reasons pointed out in 4.1. However, results of ANN revealed a MAPE of $2.50 \%$ for same number of days considered in year 2012.

\section{Conclusions}

Two forecasting models are developed and presented in this paper for the prediction of next day peak electricity demand of Sri Lanka power system. Peak demand of Sri Lanka is mostly affected by features such as day of the week, temperature, Relative Humidity, PB or a PBM and full moon day. Special features such as whether the day is falling on a New Year week or a Wesak week has also shown some effect on the system night peak demand. Unprecedented events like ODIs and T20s has also shown some effect on the peak demand and is interestingly noted. The above features are carefully treated and analysed using widely used load prediction models such as traditional MRA statistical model and an alternative model which does not rely on human experience i.e. ANN. The Mean Absolute Percentage Error while predicting peak demand for the calendar year 2012 using MRA is found to be $4.72 \%$ where as using ANN is $2.50 \%$. Since ANN is giving the lowest MAPE, it can be concluded that the Artificial Neural network model is the best fit model that can be used to forecast the Daily peak demands of Sri Lanka. Since the process is an adaptive method of forecasting procedure, it has to be updated at the end of each year. Such an updated exercise carried out 
for the first four months of the year 2013 is shown in figure 5. Developed ANN model for the year 2013 gives the Mean Absolute Percentage Error of $2.08 \%$ for 110 out of 120 consistent data in the period of $01 / 01 / 2013$ to 30/04/2013.
4. Eugene A. Feinberg \& Dora Genethliou "Load forecasting", Applied Mathematics for Restructured Electric Power Systems: Electric Power Systems: Optimization, Control, and Computational Intelligence (J. H. Chow, F.F. Wu, and J.J. Momoh, eds.), Spinger, USA, 2005, pp. 269-285

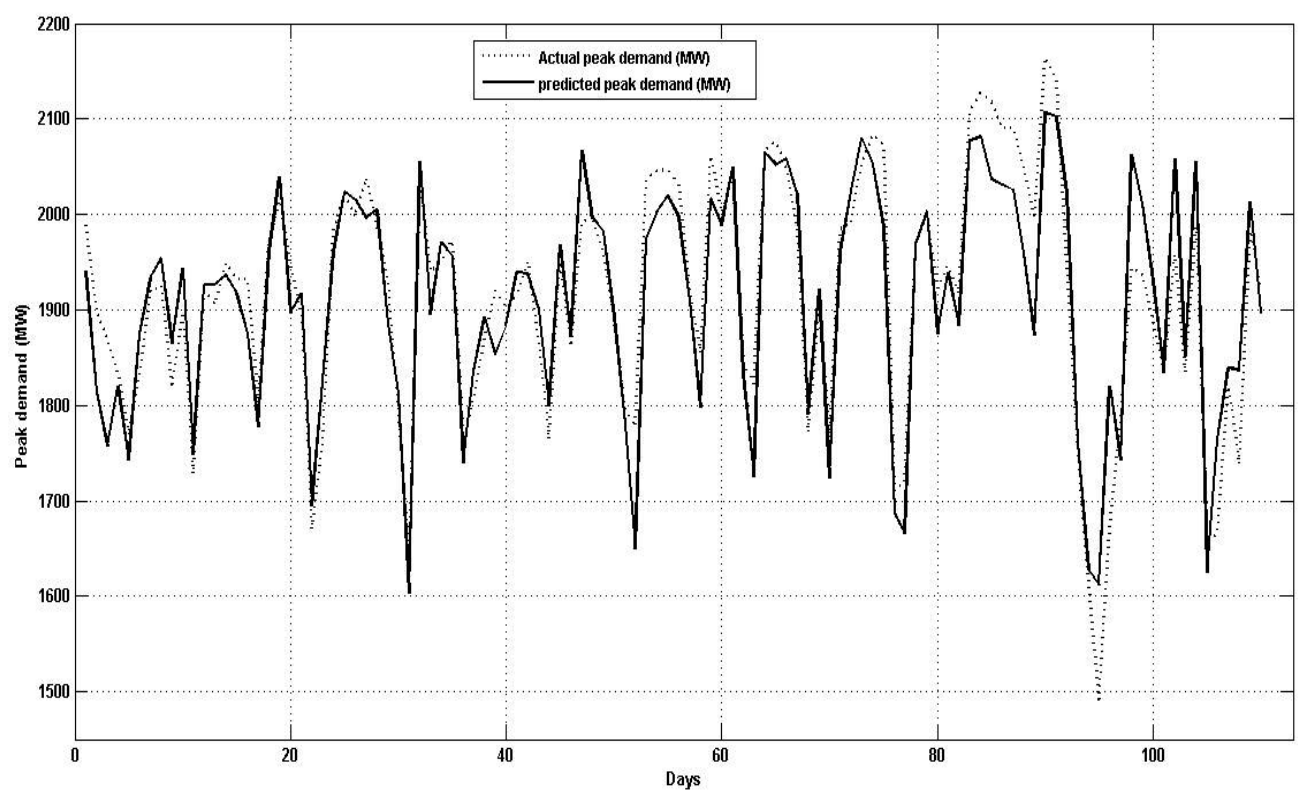

Figure 5 - Plot of Actual Vs Predicted values for the period of 01/01/2013 to 30/04/2013

\section{Acknowledgement}

The authors would like to offer his appreciation and thanks to Eng. J. Nanthakumar, CEB System Control Centre for his assistance given during data collection, many helpful comments and suggestions. Also the guidance provided by Dr. Narendra de Silva of LECO, Dr. (Mrs) D.D.M. Ranasinghe and Dr. (Mrs) H.U.W. Rathnayake of OUSL is greatly appreciated.

\section{References}

1. Spyros makridakis and Steven C. Wheelwright, Forecasting methods and Applications, Jhon Wiley \& Sons,USA,1978.

2. Elaine Rich, Kevin Knight, Shivashankar B Nair, Artificial Intelligence, $3^{\text {rd }}$ ed , The McGraw- Hill Companies, New Delhi , India, 2009.

3. Kevin L. Priddy and Paul E. Keller, Artificial Neural Networks an Introduction, 1st ed, PrenticeHall of India Private Limited, New Delhi ,India, 2007.
5. Amral N., Özveren C. S., King D., "Short Term Load Forecasting using Multiple Linear Regression", Proc of UPEC , 42 nd international, September, 2007, pp 1192- 1198.

6. Tilakasena D. K Bandula, “Country Presentation Sri Lanka", Presentation of Technical Session-I: (USAID SARI/ Energy) Regional Clean Coal Partnership Programme, Kolkata, INDIA, September 16-19, 2008, p. 7.

7. Al-Shareef A. J., Mohamed E. A. and E.AlJudaibi, "Next 24-Hours Load Forecasting using Artificial Neural Network (ANN) for the Western Area of Saudi Arabia", J. Faculty of Eng.Sci, King Abdulaziz University (KAU) , Vol.19, No.2, 2008, pp. 25-40.

8. Adepoju G. A., Ogunjuyigbe S. O. A., and Alawode K. O., "Application of Neural Network to Load Forecasting in Nigerian Electrical Power System", The Pacific journal of Science and Technology, Akamai University, Vol. 8, No 1, May, 2007. 
9 Alexandra KOTILLOVÁ, “Very Short- Term Load Forecasting using Exponential Smoothing and ARIMA models", Journal of information, Control and Management Systems, Vol. 9, No. 2, 2011.

10. Howard Demuth, Mark Beale, "Neural Network Toolbox User's Guide", 6th ed, Version 4 (Release 12), Copyright by The MathWorks, inc., September, 2000, chap. 2, 3, 5.

11. http://www.slideserve.com / Rita / regression - outliers, Visited, 13 th June 2011.

12. http://www.duke.edu / rnau / testing.htm Visited, 20th June 2011.

13. http://www.wunderground.com, Visited and recorded the weather data of each day from $01 / 01 / 2008$ to $30 / 04 / 2013$.

14. http://www.ceb.lk, Visited and recorded the peak demand of each day from 01/01/2012 to 30/04/2013. 


\section{Appendix A1}

Method of selecting best Multiple Regression Model

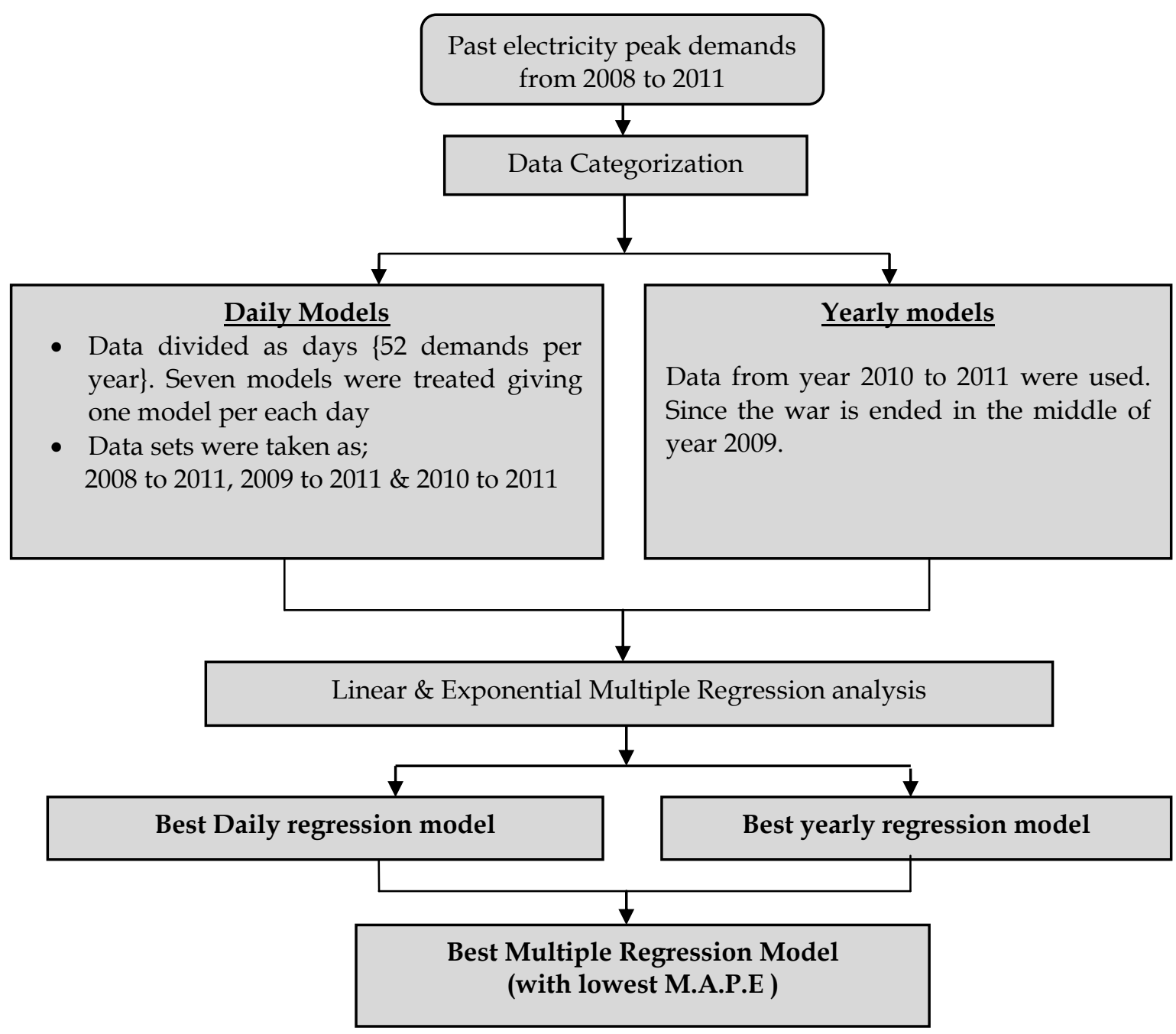

Figure A1 - Algorithm for the development of best MRA model

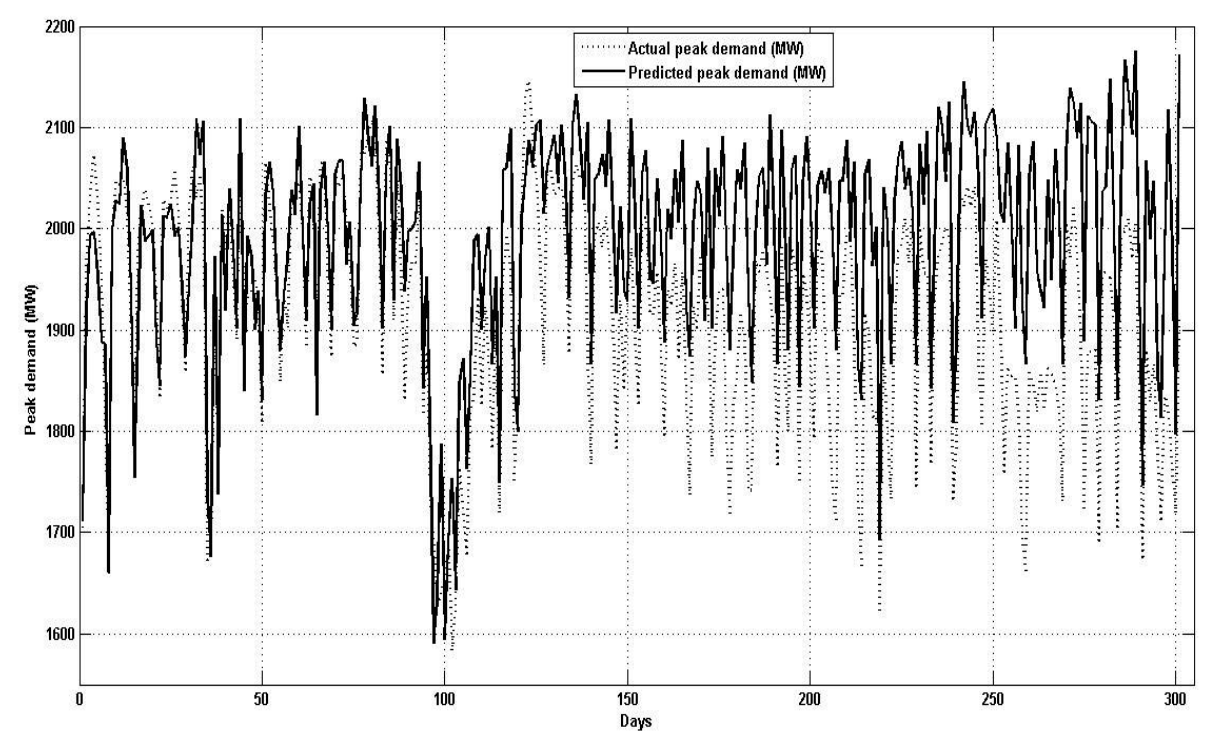

Figure A2 - Actual Vs Predicted values for year 2012 by MRA model 


\section{Appendix A2}

Method of selecting best neural network structure

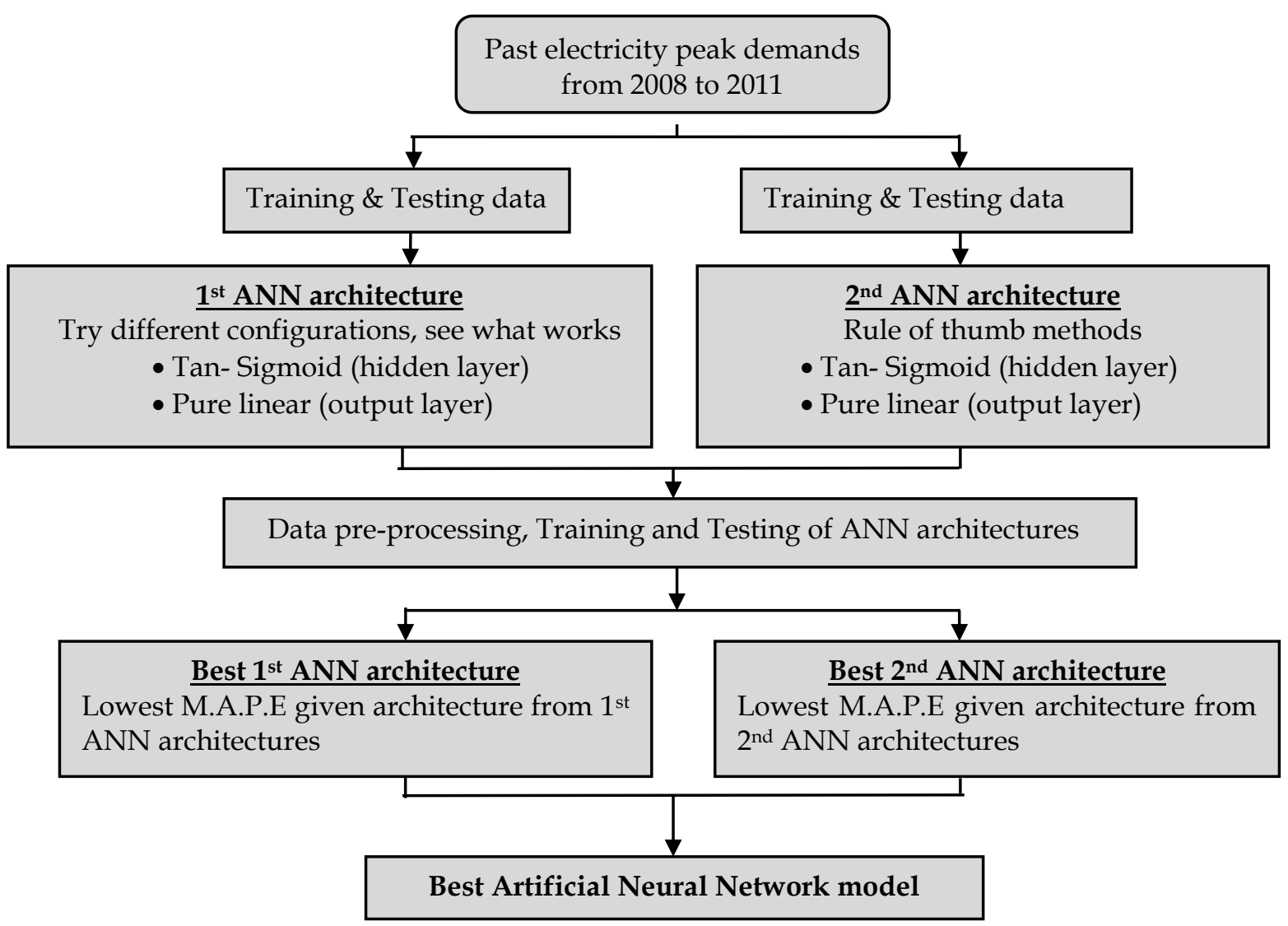

Figure A1 - Algorithm for the development of best ANN Structure

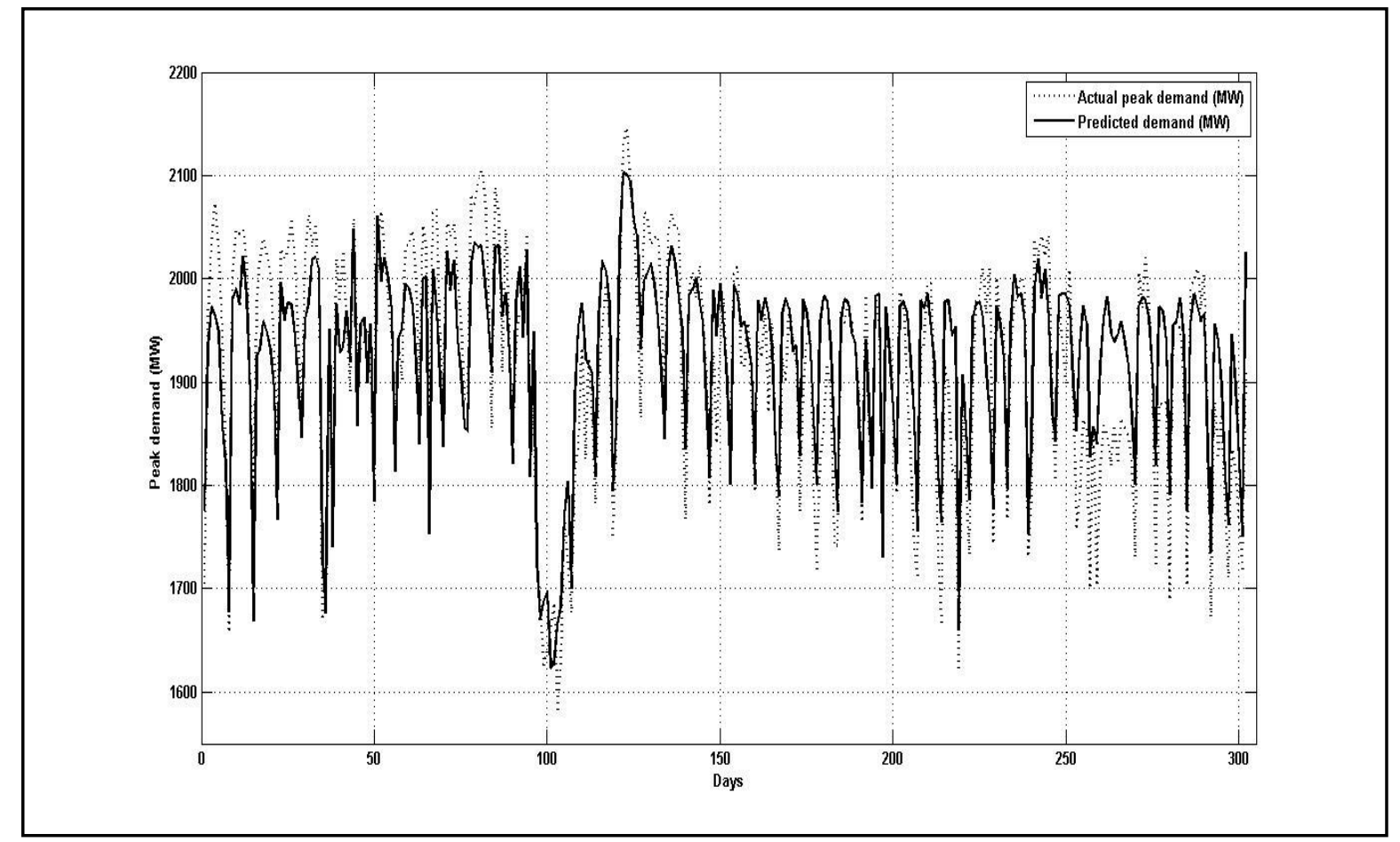

Figure A2 - Actual Vs Predicted values for year 2012 by ANN model 